\title{
AN EVALUATION OF TWO COMPOSITE MEDIA FOR PRELIMINARY IDENTIFICATION OF SHIGELLA AND SALMONELLA
}

\author{
BY \\ R. R. GILLIES \\ From the Department of Bacteriology, University of Edinburgh
}

(RECEIVED FOR PUBLICATION NOVEMBER 25, 1955)

Because of the great demand for bacteriological examination of faecal specimens for Salmonella and Shigella organisms, there is need for a simplified biochemical method of preliminary differentiation of the Enterobacteriaceae to replace the widely used differential set of sugars involving inoculation of six or more tubes of separate media. The basic requirements of such a method are that it should be as accurate and reliable as the conventional method, and should effect economies in time, labour, and materials. An obvious way of effecting these economies is by using composite media, thus testing two or more biochemical or other characteristics in one culture tube.

In 1911 Russell introduced a double-sugar medium for testing fermentation of glucose and lactose respectively in the depth and at the surface of the medium. Numerous modifications have since been introduced. Krumwiede, Pratt, and McWilliams (1916) substituted Andrade's indicator for the original litmus to obtain sharper colour changes and allow readings to be made in artificial light. Krumwiede and Kohn (1917) added 1\% of sucrose to exclude " many 'intermediates' which have a greater avidity for sucrose than for lactose when grown aerobically." Kligler (1918), by incorporating lead acetate in the medium, offered a method of differentiating $S$. typhi from the Shigellae, and, in association with Defandorfer (1918), substituted mannitol for lactose in Russell's original recipe, thus permitting differentiation between Shiga and Flexner types of dysentery bacilli. More recent modifications (Hajna, 1945; Bader and Hotz, 1951) indicate the limit of biochemical characteristics which can profitably be tested by a single-tube composite medium. Recently, Kohn (1954) described a technique employing two composite media, and this paper gives the results obtained by using his media in routine diagnosis in comparison with the conventional method normally used in the biochemical selection of pathogenic organisms before serological identification.

\section{Materials and Methods}

Composite Medium I.-Composite medium I consisted of beef extract, 2 g., proteose peptone No. 3 (Difco), 15 g., yeast extract, 2 g., glucose, 1 g., mannitol, 10 g., agar, $16 \mathrm{~g}$., indicator mixture, $26.5 \mathrm{ml}$., distilled water, $1,000 \mathrm{ml}$. ; $p \mathrm{H}=7.2$. After autoclaving at $10 \mathrm{lb}$. for 15 minutes and cooling to $60^{\circ} \mathrm{C}$., $50 \mathrm{ml}$. of a sterile $20 \%$ urea solution was added and the medium was distributed aseptically in sterile testtubes to a depth of $6.5 \mathrm{~cm}$. and allowed to solidify in a sloped position so as to provide a butt of $2.5 \mathrm{~cm}$. The indicator used was the bromo-thymol blue-cresol red-thymol blue mixture of Singer (1950), which gives a better differentiation of urease-producing and alkali-forming organisms than the indicators suggested by Kohn.

Composite Medium II.-Composite medium II consisted of agar, 3 g., bacto-peptone (Difco), 10 g., tryptone (Difco), 10 g., $\mathrm{NaCl}, 5$ g., $\mathrm{Na}_{2} \mathrm{HPO}_{4} 12 \mathrm{H}_{2} \mathrm{O}$, 0.25 g., sucrose, 10 g., salicin, 10 g., bromothymol blue, 0.01 g., $\mathrm{Na}_{2} \mathrm{~S}_{2} \mathrm{O}_{3} .5 \mathrm{H}_{2} \mathrm{O}, 0.025$ g., distilled water, $1,000 \mathrm{ml}$. $p \mathrm{H}=7.4$. The medium was distributed into test-tubes in $8 \mathrm{ml}$. amounts, autoclaved at $15 \mathrm{lb}$. for 15 minutes, and allowed to set with the tubes in the vertical position. This recipe differs from Kohn's in that the amount of $\mathrm{Na}_{2} \mathrm{HPO}_{4} \cdot 12 \mathrm{H}_{2} \mathrm{O}$ has been halved and the amounts of both sugars doubled; these minor modifications result in more clear-cut fermentation reactions.

Test Papers.-Strips $(5 \mathrm{~mm} . \times 50 \mathrm{~mm}$.) of filter paper were impregnated with saturated lead acetate and dried in an oven at $70^{\circ} \mathrm{C}$. Indole test papers were similarly impregnated with the following solution: p-dimethyl-aminobenzaldehyde, 5 g., methanol, $50 \mathrm{ml}$., o-phosphoric acid, $10 \mathrm{ml}$., and were dried at $70^{\circ} \mathrm{C}$. for a minimum period.

Method of Testing.-The two media were inoculated with a long straight wire charged from a pure 
culture of the organism to be identified; medium I was inoculated by both smearing the slant and then stabbing to the base of the butt; medium II was then inoculated by a single stab into its upper $\frac{1}{2}$ inch ; finally, the two test papers were suspended above the latter medium and held by the cotton-wool stopper. The conventional method of testing for fermentation of glucose, lactose, dulcite, sucrose, and mannitol, the production of indole, and for motility was that given by Mackie and McCartney (1953). By this method of identification at least six culture tubes were inoculated.

Source of Cultures.-The organisms were isolated from plates of MacConkey's or desoxycholate-citrateagar medium which had been inoculated from specimens of faeces or rectal swabs submitted for investigation from cases of dysentery or enteric infection; pale colonies, presumably non-lactose fermenters, were subcultured on nutrient agar slopes, and after eight hours' incubation at $37^{\circ} \mathrm{C}$. the growth was used to inoculate the composite and the conventional media which were then incubated for 18 to 24 hours at $37^{\circ} \mathrm{C}$.; the results with each set of media were noted by independent observers, each organism being provisionally identified as Salmonella, Shigella, or as " nonpathogenic"; finally, complete serological confirmation of the identity of all pathogenic organisms was made in accordance with the routine diagnostic practice.

\section{Results}

In the modified composite media presented, the following characteristics can be noted ; in medium I the fermentation of glucose is indicated by the butt changing from deep green to yellow, and that of mannitol by the development of a yellow slant. Urease production (frequently noted after two to three hours) produces a deep blue colour throughout the medium; gas production appears in varying degrees from a slight splitting along the wire track to disruption of the medium ; in medium II, fermentation of sucrose and/or salicin changes the medium from light blue to yellow and accompanying gas production causes bubbles to form; nonmotile organisms grow only along the line of inoculation whereas motile species show either a diffuse, even growth spreading from the inoculum or, more rarely, localized outgrowths which are usually fan-shaped or occasionally nodular. Production of $\mathrm{H}_{2} \mathrm{~S}$ causes blackening of the lead acetate paper. The formation of indole gives a red colour in the yellow test paper, but false negative reactions were noted when fermentation had occurred in the medium, although such reactions were fewer than when Kovac's reagent was used as recommended by Kohn; another advantage of the paper-test compared with layering of Kovac's reagent on the surface of the medium is that this reagent, being highly acid, discolours the medium and thus renders reincubation for further study valueless.

Table I details the various reactions obtained in the composite media, and Table II gives the serological types of Salmonella (other than S. typhi) and of Sh. flexneri identified. Two thousand, one hundred and eight organisms have so far been

\section{TABLE I}

IDENTIFYING PATTERNS OF ORGANISMS BY THE COMPOSITE MEDIA (18 HOURS' INCUBATION AT $37^{\circ}$ C.)

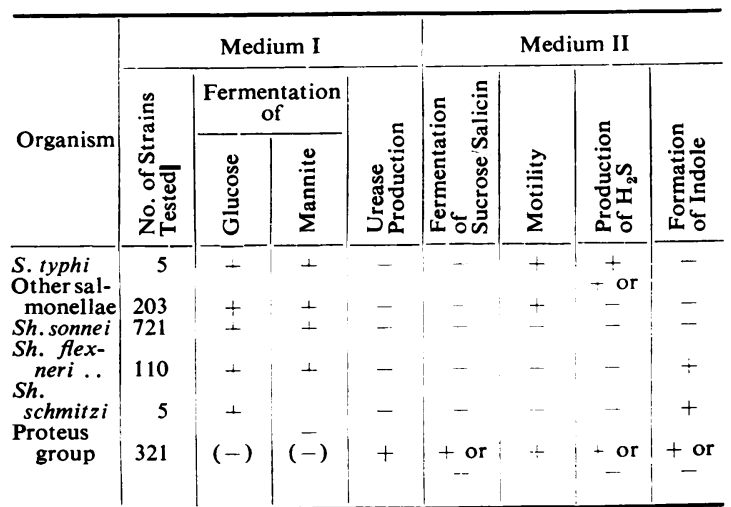

Fermentation tests: $+=$ acid and gas produced. $\perp=$ acid only. $-=$ no reaction. + or $-=$ variable reaction. $(-)=$ apparent nega:ive reaction, urease activity masks effects of fermentation. Other tests : $+=$ positive. $-=$ negative. + or $-=$ variable reaction.

TABLE II

NO. OF DIFFERENT SEROLOGICAL TYPES OF SALMON. ELLA (OTHER THAN S. TYPHI) AND OF $S H$. FLEXNERI IDENTIFIED

\begin{tabular}{|c|c|c|c|c|c|}
\hline \multicolumn{3}{|c|}{$\begin{array}{l}\text { Type of } \\
\text { Salmonella }\end{array}$} & $\begin{array}{l}\text { No. of } \\
\text { Strains }\end{array}$ & $\begin{array}{l}\text { Type of } \\
\text { Sh. flexneri }\end{array}$ & $\begin{array}{l}\text { No. of } \\
\text { Strains }\end{array}$ \\
\hline $\begin{array}{l}\text { S. typhi murium } \\
\text { S. paratyphi } B . \\
\text { S. aberdeen } \\
\text { S. derby } \\
\text { S. thompson } \\
\text { S. bareilly } \\
\text { S. worthington } \\
\text { S. hvittingfoss } \\
\text { S. give } \\
\text { S. muenchen } \\
\text { S. montevideo }\end{array}$ & $\begin{array}{l} \\
\cdots \\
\cdots \\
\cdots \\
\cdots \\
\cdots \\
\cdots \\
\cdots \\
\cdots \\
\cdots\end{array}$ & \begin{tabular}{l|l|}
$\cdots$ & \\
$\cdots$ & \\
$\cdots$ & \\
$\cdots$ & \\
$\cdots$ & \\
$\cdots$ & \\
$\cdots$ & \\
$\cdots$ & \\
$\cdots$ &
\end{tabular} & $\begin{array}{r}98 \\
28 \\
20 \\
10 \\
8 \\
8 \\
8 \\
7 \\
6 \\
6 \\
4\end{array}$ & $\begin{array}{l}1 \mathrm{a} \\
3 \\
4 a\end{array}$ & $\begin{array}{r}3 \\
60 \\
47\end{array}$ \\
\hline Total & $\ldots$ & $\bar{\cdots}$ & 203 & Total & 110 \\
\hline
\end{tabular}

identified by the composite media in parallel with the conventional method; according to the biochemical reactions of the latter method 208 organisms were grouped as Salmonella, 836 as Shigella, and 1,064 as "non-pathogenic"; by the composite media the figures were respectively 226 , 836 , and 1,046 . The 18 organisms (less than $1 \%$ of the total) identified as Salmonella by the composite media but as non-pathogenic by the conventional method gave negative serological find- 
ings and were shown to differ biochemically from the Salmonella group only in fermenting lactose. Three Salmonella strains which showed motility macroscopically in medium II (and identified as $S$. paratyphi $B$. serologically) were non-motile as judged by the hanging drop preparation from the peptone water culture of the conventional method, and these required subculture in Craigie tubes before being found motile.

One hundred and eighty-seven of the organisms were inoculated directly into the composite media from single colonies on MacConkey's or desoxycholate-citrate-agar medium and the results were as readily interpreted as those obtained when growth from an eight-hour subculture on nutrient agar slopes was used as an inoculum. It appears that such preliminary subculture could be omitted in routine practice.

\section{Discussion}

The results obtained in this investigation suggest that the composite media described offer a suitable means for preliminary selection of Salmonella and Shigella organisms before the serological confirmation of their identity. No organisms were wrongly identified as "non-pathogenic" by use of these media. Reference has been made to the provisional inclusion of 18 organisms of the Salmonella group, which on further investigation were shown to be non-pathogenic. These few instances reflect the uncertainty of selecting organisms as non-lactose fermenters on the basis of the "pale" appearance on desoxycholatecitrate or MacConkey media.

To eliminate these 18 cultures required the unnecessary serological testing of only $1.69 \%$ of the 1,062 organisms selected; many will consider that this is a small price to pay for the general saving in time, labour, and glassware resulting from use of the composite media in place of the usual set of sugar media. If it is considered that such a proportion of unnecessary serological investigations is too great they may be avoided by using a lactose-peptone-agar slope in place of the nutrient agar slope normally employed for subculturing "pale" colonies before inoculating the composite media.

It is of interest to compare the results obtained by Bader and Hotz in using a one-tube iron-ureaagar medium with the two composite media used in the present inquiry. These authors picked 430 colonies from desoxycholate-citrate-agar plates and were able to discard 299 of these as non-pathogenic after 18 hours' incubation; the remaining 131 cul- tures required subculture on other media before 16 Salmonella and two Shigella strains were selected for serological confirmation of identity. All such one-tube composite media are of limited value since at least $20-30 \%$ of cultures require further biochemical investigation before being serologically identified.

More ambitious techniques have been devised with the intention not of screening cultures for further investigation but of permitting full biochemical identification into the various groups of Enterobacteriaceae (Silberstein and Rabinowitz, 1950 ; Colichón, 1953), but these techniques involve the use of complex media and are employed in such a manner as to make their use in a busy diagnostic laboratory questionable; nor do these methods give such complete information as the two composite media used in the present investigation. One great value of these latter media is the inclusion of a macroscopic motility test, the advantages of which compared with the hanging-drop method have been noted by Tittsler and Sandholzer (1936). The "storage-life" of these media in bulk in screw-cap containers is at least eight weeks at room temperature, and when tubed ready for use they keep for at least six weeks if stored in refrigerator.

\section{Summary}

Selection of Salmonella and Shigella organisms before serological identification was made by Kohn's technique ; the modified composite media used were evaluated by comparison with the conventional sets of sugar media.

Two thousand one hundred and eight organisms of faecal origin were examined, and by use of the composite media were grouped as 226 Salmonella, 836 Shigella, and 1,046 "non-pathogenic." The parallel use of the conventional method revealed 208,836 , and 1,064 organisms respectively in these groups.

No organisms were wrongly identified as " nonpathogenic" by the composite media ; 18 , however $(0.85 \%$ of the total examined and $1.69 \%$ of those selected for serological confirmation), were pro- $\sigma$ visionally included as Salmonella but were found $\tilde{O}$ to be serologically negative and thus correctly classed as non-pathogenic.

These results compare favourably with those obtained by the conventional method of pre- $\frac{\complement}{\Phi}$ liminary identification of Salmonella and Shigella $\stackrel{\oplus}{+}$ groups, and the adoption of the composite media 0 in routine selection of these organisms effects economies in time, labour, and glassware. 
I wish to express my gratitude to the late Professor T. J. Mackie and also to Dr. J. P. Duguid for their interest and advice; Mr. J. Sutherland gave much technical assistance in the investigation.

\section{REFERENCES}

Bader, R.-E., and Hotz, G. (1951). Z. Hyg. InfekıKr., 133, 20.

Colichón, H. (1953). Amer. J. clin. Path., 23, 506.

Hajna, A. A. (1945). J. Bact., 49, 516.
Kligler, I. J. (1918). J. exp. Med., 28, 319. and Defandorfer, J. (1918). J. Bact., 3, 437.

Kohn, J. (1954). J. Path. Bact., 67, 286.

Krumwiede, C., Jr., and Kohn, L. A. (1917). J. med. Res., 37, 225. — Pratt, J. S., and McWilliams, H. I. (1916). J. infect. Dis., 18, 1. Mackie, T. J., and McCartney, J. E. (1953). Handbook of Practical Bacteriology, p. 465, 9th ed. Livingstone, Edinburgh.

Russell, F. F. (1911). J. med. Res., 25, 217.

Silberstein, W., and Rabinowitz, K. (1950). Acta med. orient., 9, 44. Singer, J. (1950). Amer. J. clin. Path., $20,880$.

Tittsler, R. P., and Sandholzer, L. A. (1936). J. Bact., 31, 575. 